\title{
IMPLEMENTATION AND TUNING OF A FUZZY-PID CONTROL SYSTEM VIA FIELDBUS COMMUNICATION
}

\section{IMPLEMENTAÇÃO E SINTONIA DE UM SISTEMA DE CONTROLE FUZZY-PID UTILIZANDO COMUNICAÇÃO FIELDBUS}

\author{
F. V. SILVA*,1, A. M. F. FILETI ${ }^{1}$, M. R. MENEZES ${ }^{2}$ and I. C. FRANCO ${ }^{1,2}$ \\ ${ }^{1}$ University of Campinas - UNICAMP, School of Chemical Engineering, Brazil \\ ${ }^{2}$ FEI University, Department of Chemical Engineering, Brazil \\ *E-mail: flavio@feq.unicamp.br
}

\author{
article info \\ Article history: \\ Received 2017-06-23 \\ Accepted 2017-09-01 \\ Available online 2017-11-20
}

KEYWORDS: Fieldbus, Fuzzy Controller, Tuning, PID Controller

PALAVRAS-CHAVE: Fieldbus, Controlador Fuzzy, Sintonia, Controle PID.

\begin{abstract}
In research applications is very important to have a flexible automation structure for different plant conditions with a large flow of information. To satisfy real-time requirements a communication technique based in fieldbus network was used to interconnect devices in an intelligent distributed control system. Using this structure, an experimental tuning for fuzzy-PID controller based in scaling gains from a well-tuned conventional PID controller was studied in this work. Due to difficulties involving fuzzy controllers tuning (expert knowledge, adjustments in rules, membership functions and gains) it is recommended to develop a tuning procedure, which will greatly reduce the time of design. From the gains of a well-tuned conventional PID controller a hybrid velocity/position fuzzy-PID controller was designed. Experimental tests were carried out for level control in a tank system under different disturbances in set point values. Tuning performance of different conventional and fuzzy-PID structures were evaluated with respect to their functional behaviors (overshoot, rise time and ISE criterion). Results obtained showed that fuzzy controller structure has a great potential for application even when it is possible to implement a conventional PID controller. It is also observed that there is saturation of the manipulated variable for the conventional PID controller which does not occur in the fuzzy-PID controller.
\end{abstract}

RESUMO: Em pesquisas de aplicações é muito importante ter uma estrutura de automação flexível para diferentes condições da planta com grande fluxo de informações. Para satisfazer os requisitos em tempo real, utilizou-se uma técnica de comunicação baseada em rede fieldbus para interconectar dispositivos em um sistema de controle distribuido inteligente. Com essa estrutura, foi estudado neste trabalho um ajuste experimental para um controlador PID fuzzy baseado em ganhos de escala de um controlador PID convencional bem sintonizado. Devido às dificuldades que envolvem a sintonia dos controladores fuzzy (conhecimento especialista, ajuste nas regras, funções pertinência e ganhos), é recomendado desenvolver um procedimento de sintonia reduzindo assim o tempo de desenvolvimento. A partir dos ganhos de um controlador PID convencional bem ajustado, foi projetado um controle PID híbrido de velocidade/posição. Testes experimentais foram realizados para o controle de nível em um sistema de tanques sob diferentes distúrbios nos set-point. $O$ desempenho do ajuste de diferentes estruturas PID convencionais e fuzzy foi avaliado em relação aos comportamentos funcionais (overshoot, tempo de subida e critério ISE). Os resultados obtidos mostraram que a estrutura do controlador fuzzy possui um ótimo potencial de aplicação mesmo quando é possível implementar um controlador PID convencional. Também é observado que há saturação da variável manipulada para o controlador PID convencional o que não ocorre para o controlador Fuzzy-PID. 


\section{INTRODUCTION}

The fieldbus network was first introduced its non-proprietary and open protocol in 1994. This technology is defined as an all-digital, serial, two-way communications system that interconnects measurement and control equipment such as sensors, actuators and controllers. At the base level in the hierarchy of plant networks, it serves as a Local Area Network (LAN) for instruments used in process control and manufacturing automation applications and has a built-in capability to distribute the control application across the network. The demand for fieldbus technology is being driven by manufacturing and users desire to move away from older, centralized plant control strategies to distributed control in the field (PELUSO, 1996; LEE et al., 2004)

Significant improvements have been seen in advanced controllers over the last years. However, linear PID controller is still applied extensively in industrial practice. The reason lies in its robustness and well-known control design and implementation, although assumptions, simplifications, or lumping parameters are often made to build a mathematical model that may be far from the real situation.

In process control the behavior of most physical systems is nonlinear. Linear control may be effective for local operation, but it is inadequate for controlling operations over a broad range. Thus, interest in fuzzy controllers has been growing because of its simplicity and versatility when implemented in complex and nonlinear processes (SANTOS and DEXTER, 2002).

The concepts of fuzzy logic control were first proposed by Zadeh (1965). Was observed by Zadeh (1965) that the technology used at the time was not able to express the degree of ambiguity in human thinking and relating it to chemical and biological processes. The fundamental idea behind fuzzy logic is basically to use an operator knowledge expert, enabling the computers to make human-like decisions.

Successful applications of fuzzy controllers have been applied to various processes. These applications include control in refrigeration systems (APREA et al., 2004; EKREN and KUÇUKA, 2010; SILVA et al., 2011; VIDAL et al., 2016; FRANCO et al., 2017); in biodiesel reactor (BABUSKA and VERBRUGGEN, 1996; EKER and TORUN, 2006; FONSECA, et al., 2016); in polymerization reactor (FILETI et al., 2007; WAKABAYASHI et al., 2009); in bioreactor (FONSECA et al., 2013) and successful application to nonlinear and real-world processes control (FUENTE et al., 2006; LIAO et al., 2008; PRECUP and HELLENDOORN, 2011).

Due to implication in the performance of the controllers, efficient tuning methods are highly desirable. For linear PID controller several tuning rules are available to cover wider range of process specification. Ziegler-Nichols (step response method and frequency response method) and Åström-Hägglund are two of the most common direct tuning methods applied in industrial control. However, fuzzy controllers are still not so common in industrial practice. The main reason for that being its difficult tuning procedure. A significant effort in tuning fuzzy controllers has been concentrated on different control structures. 
In this study, a comparative experimental design and tuning of fuzzy-PID and PID controllers were applied using SISO strategy. The present work involves a performance analysis of the fuzzy-PID with scaling gains, and linear PID controller for level control in a tank system, under different disturbances in set point values using digital fieldbus communication. Gain design was based on the well-tuned PID controller and the methodology of tuning was based on the analogy between the scaling gains and gains from linear PID controller (LI, 1997).

\section{DESIGN OF CONTROLLERS}

\subsection{PID controller}

PID is a control algorithm extensively used in industrial control. It is widely implemented in industrial single loop controllers, distributed control systems (DCS) and programmable logic controllers (PLC). PID controller uses the error (e) as input and generates a controlled pulse number into the controlled variable. Its mathematical representation can be defined by Eq. (1):

$$
u_{P I D}=u_{s}+K_{c}\left\{e(t)+\frac{1}{\tau_{i}} \int_{0}^{t} e(t) d t+\tau_{d} \frac{d e(t)}{d t}\right\}
$$

The first step in the PID controller design is to tune its parameters $K_{c}, \tau_{i}$ and $\tau_{d}$ (proportional gain, the integral time and derivative time, respectively). Several tuning methods have been proposed for PID controller. Ziegler-Nichols methods (frequency response method and reaction curve method) or Åström \& Hägglund method are usually applied in industrial practice.

\subsection{Fuzzy-PID controller.}

Fuzzy controller is the most successful application of fuzzy logic in terms of both theoretical and experimental researches. The main characteristic of this controller is to utilize operator's knowledge and experience to obtain a better control action and to reduce system error to a minimum. While most of the modern controllers need a formal mathematical model, a fuzzy controller do not required it. A satisfactory nonlinear control can be developed empirically without complicated mathematics.

Conventional structure of a fuzzy-PID controller has three inputs (e: error, $\Delta \mathbf{e}$ : error increment and $\Delta^{2} \mathbf{e}$ : rate of error increment) and a three-dimensional rule base, which makes the design task more complex. Different combinations are also possible, using two terms fuzzy-PI and fuzzy-PD controllers.

Fuzzy-PI control is known to be more commonly used than fuzzy-PD once it is difficult for fuzzy-PD to remove the steady state error. However, fuzzy-PI doesn't show a good performance in the non-steady state conditions (LI, 1996). By combining both fuzzy-PI and fuzzy-PD actions a two term fuzzy-PID controller (e:error and $\Delta \mathbf{e}$ :error increment) can be formed. This structure is called hybrid velocity/position-type fuzzy-PID controller, as 
shown in Figure 1 (LI, 1997).

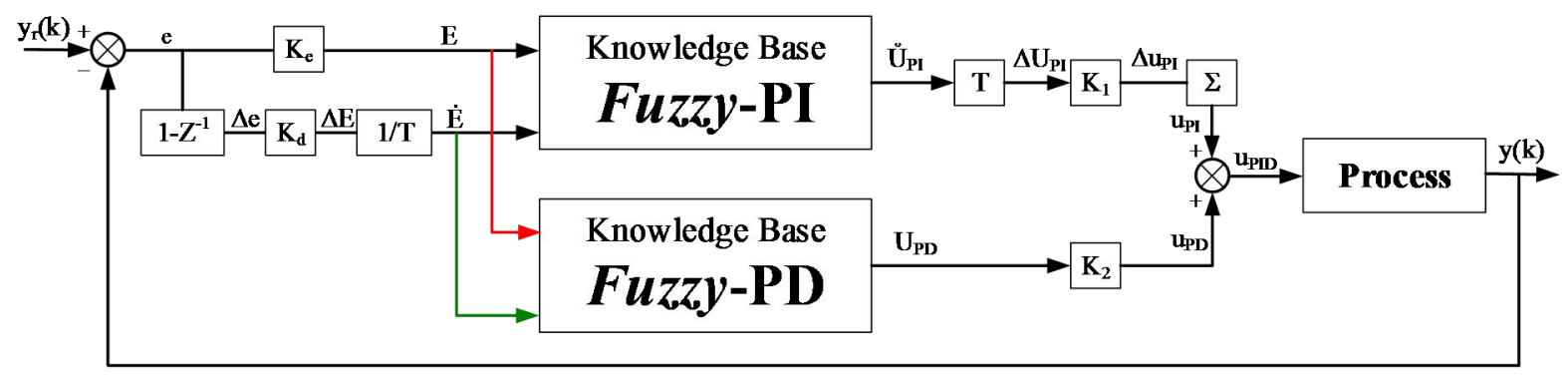

Figure 1 - Digital structure of a hybrid velocity/position fuzzy-PID controller.

Hybrid fuzzy-PID controller has two inputs (error and error increment) and one output that could be defined by Eq. (2-4):

$$
\begin{aligned}
& e(k)=y_{r}(k)-y(k) \\
& \Delta e(k)=e(k)-e(k-1) \\
& u_{P I D}(k)=u_{P I}(k)+u_{P D}(k)
\end{aligned}
$$

Where $y_{r}, y$ and $u$ are the desired set point, plant output and controller output, respectively. The indexes $k$ and $(k-1)$ indicate the present state and the previous state of the system, respectively. The integral action in fuzzy-PI output $\left(\mathrm{U}_{\mathrm{PI}}\right)$ and the derivative action in input was approximated by $\Delta_{P I}=U_{P I} T$ and $\dot{E}=\Delta E / T$, respectively.

Fuzzy controller design comprises basically the definition of a set of terms used to input and output variables, their respective membership functions, the rule base (which represents the specialist system knowledge) and gain adjustment. However, tuning stage becomes also difficult and hard-working due to simultaneous multiple adjustment (LI, 1996; HABER and GUERRA, 1999). Gains (or scaling factors) $K_{e}, K_{d}, K_{1}$ and $K_{2}$ are used for tuning the response, playing a similar role to that of the gains of a conventional PID controller.

\section{Process Control Plant}

Figure 2 shows a simplified flow diagram of the tank system for level control implemented in this study. The instrumentation applied is represented according to the ISAS5.1 norm. The purpose of this system is to test the operation of control loops using conventional and a hybrid fuzzy-PID controllers. Using state-of-the-art technology (Fieldbus Communication), implementation of control loops were carried out using the same instrumentation available commercially for industrial control purposes.

Fieldbus devices for measuring flow rates and levels are available in the level plant, as well as positioners for use with valves and actuators. The liquid level in the tank was controlled using a control valve in the input liquid flow. Digital communication is 
accomplished with FOUNDATION ${ }^{\mathrm{TM}}$ Fieldbus protocol.

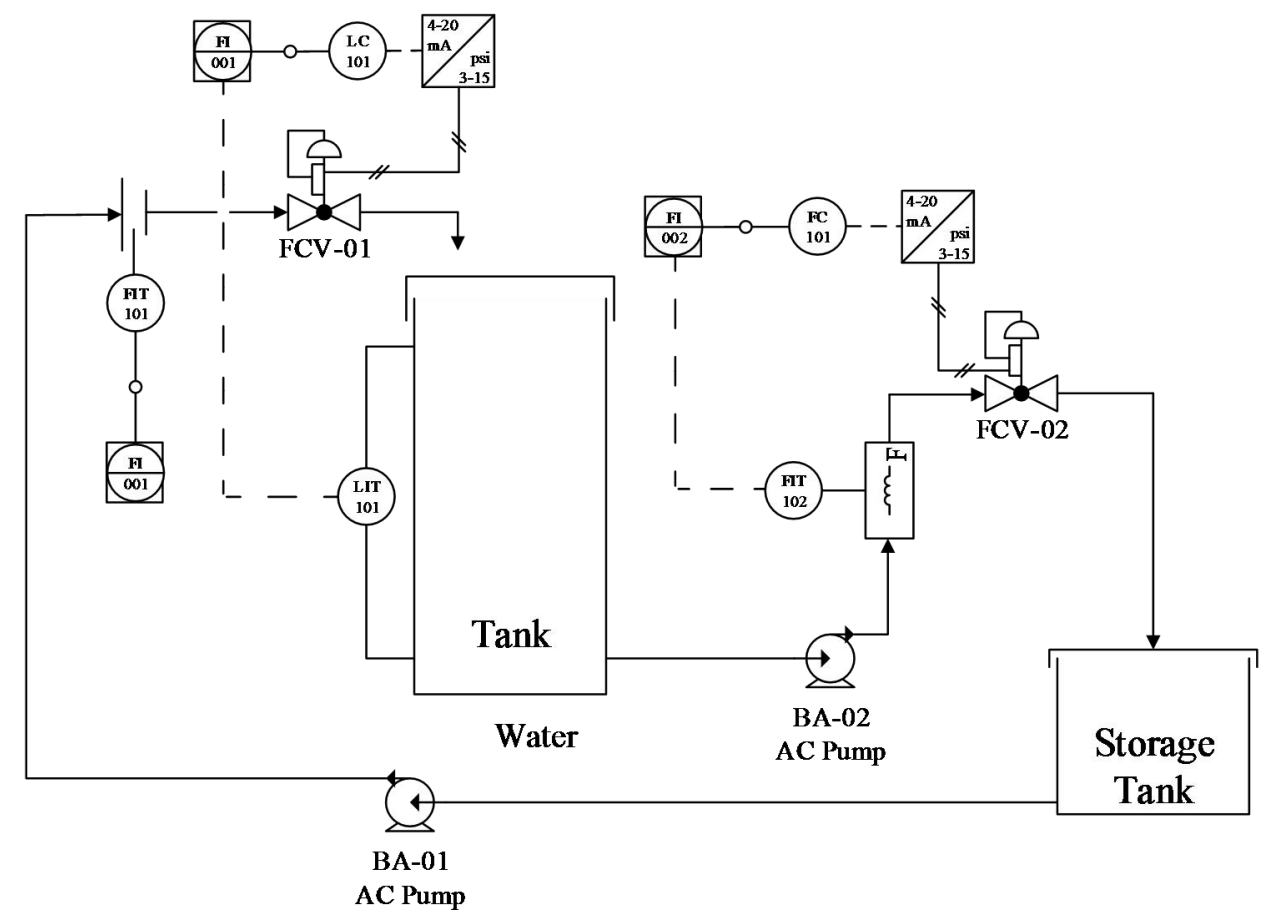

Figure 2 - Flow diagram of the process control plant.

The system was monitored and operated from microcomputer, and supervision software actuated the control systems while the plant was in operation, allowing remote process control. Data acquisition was carried out using several devices and this data were subsequently presented using animated displays.

\section{FUZZY-PID TUNING}

In order to evaluate the performance of the controllers, the system was maintained at the predefined steady state condition (level in 50\%), and then was imposed positive and negative disturbances on the set point level $( \pm 10 \%$ and $\pm 20 \%)$. Tuning of fuzzy-PID controller scaling factors was performed from well-tuned PID controller gains, using the Eq. (5-9) (LI, 1997):

$$
\begin{aligned}
& K_{d}=\alpha K_{e} \\
& K_{1} \geq \frac{K_{C}}{(\alpha+\beta)} \\
& K_{2}=\beta K_{1} \\
& \alpha+\beta \approx \tau_{I} \\
& \alpha \beta \approx \tau_{I} \tau_{d}
\end{aligned}
$$


The input (error and error increment) and output (control valve position and its increment) membership functions were composed of seven triangular and symmetric fuzzy sets. All membership functions were defined on the usual normalized universe of discourse [$1 ; 1]$ as showed in Figure 3. The input and output fuzzy sets were labeled positive large (PL), positive medium ( $\mathrm{PM})$, positive small $(\mathrm{PS})$, zero $(\mathrm{ZR})$, negative small $(\mathrm{NS})$, negative medium (NM), and negative large (NL).

Rule base for fuzzy-PI and fuzzy-PD are shown in Table 1, according to the model proposed by $\mathrm{Li}$ (1996). The adopted defuzzification method, for fuzzy outputs, was based on the determination of the center of gravity. Mandani-type inference method was used. This method tests the magnitudes of each rule and selects the highest one.

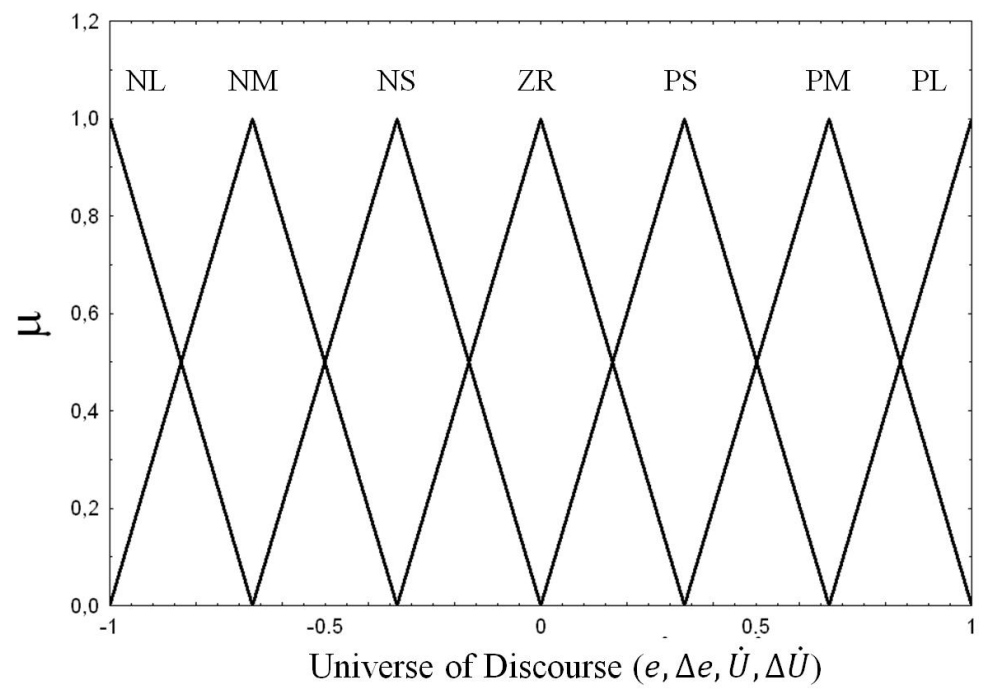

Figure 3 - Input and Output Membership Function.

Table 1 - Rule base of the fuzzy-PI and fuzzy-PD controllers

\begin{tabular}{|c|c|c|c|c|c|c|c|}
\hline \multicolumn{8}{|c|}{ Fuzzy-PI controller } \\
\hline$\Delta \mathbf{e}(\mathbf{k}) \mid \mathbf{e}(\mathbf{k})$ & NL & NM & NS & ZR & PS & $\mathbf{P M}$ & PL \\
\hline PL & $\mathbf{Z R}$ & PS & PM & PL & PL & PL & $\overline{P L}$ \\
\hline PM & NS & $\mathbf{Z R}$ & PS & PM & PL & PL & PL \\
\hline PS & NM & NS & ZR & PS & PM & PL & PL \\
\hline ZR & NL & NM & NS & ZR & PS & PM & PL \\
\hline NS & NL & NL & NM & NS & $\mathbf{Z R}$ & PS & PM \\
\hline NM & NL & NL & NL & NM & NS & ZR & PS \\
\hline NL & NL & NL & NL & NL & NM & NS & $\mathbf{Z R}$ \\
\hline \multicolumn{8}{|c|}{ Fuzzy-PD controller } \\
\hline \begin{tabular}{l|l|l}
$\Delta \mathbf{e}(\mathbf{k})$ & $\mathbf{e}(\mathbf{k})$ \\
\end{tabular} & NL & NM & NS & $\mathbf{Z R}$ & PS & $\mathbf{P M}$ & PL \\
\hline PL & NS & NS & NS & PS & PL & PL & PL \\
\hline PM & NS & NS & NS & PS & PL & PL & PL \\
\hline PS & NM & NS & NS & PS & PM & PL & PL \\
\hline ZR & NL & NM & NS & ZR & PS & PM & PL \\
\hline NS & NL & NL & NM & NS & PS & PS & PM \\
\hline NM & NL & NL & NL & NS & PS & PS & PS \\
\hline NL & NL & NL & NL & NS & PS & PS & PS \\
\hline
\end{tabular}




\section{RESULTS AND DISCUSSION}

A comparative study between a PID controller and fuzzy-PID controller was performed. First, experimental tests were carried out applying $\pm 10 \%$ set point disturbance at the liquid level. Secondly, the same tests were carried out within the range of $\pm 20 \%$ of the liquid level.

The time-integral performance criterion (integral of the square error, ISE) based on the entire response of the process was used to evaluate the error behavior and is expressed by the Eq. (10):

$$
I S E=\int_{0}^{\infty} e^{2}(t) d t
$$

The Ziegler-Nichols Method (Ultimate Gain) was used to tune optimally the PID controller parameters. Fine-tuning procedure was performed in order to achieve a appropriate response, obtaining the following tuned parameters: $K_{c}=10.0, \tau_{i}=5.9$ and $\tau_{d}=1.8$. The initial scaling gains of fuzzy-PID controller were calculated from the well tuned parameters of the PID controller. After a fine-tuning, the following values were obtained: $K_{e}=1.0, K_{d}=2.3$, $K_{l}=3.0$ and $K_{2}=19.8$. Input and output membership functions were also adjusted in order to improve the steady state and transient responses. All changes were based in preliminary knowledge of the level control system. Thus, it is possible to combine fast response and accuracy in the fuzzy-PID controller.

Figures 4 and 5 show the system performance for both controllers tested (conventional PID and fuzzy-PID) under $\pm 10 \%$ and $\pm 20 \%$ set-point disturbances, respectively and the variable controlled (level) were considered as deviation variables. The behavior of manipulated variable (control valve steam position) was also plotted in those figures.
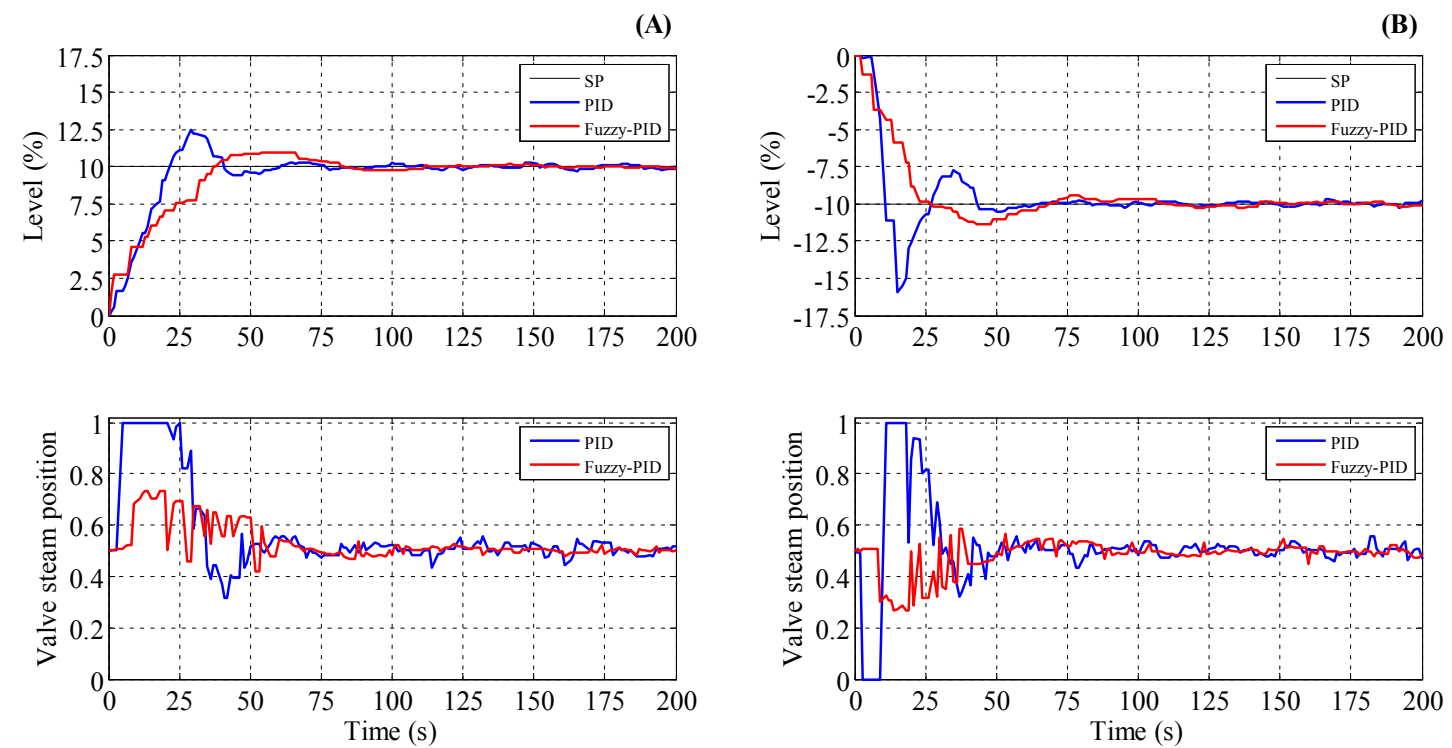

Figure 4 - Comparative behavior of fuzzy-PID and PID Controllers: (A) $+10 \%$ set point disturbances and (B) $-10 \%$ set point disturbances. 
(A)
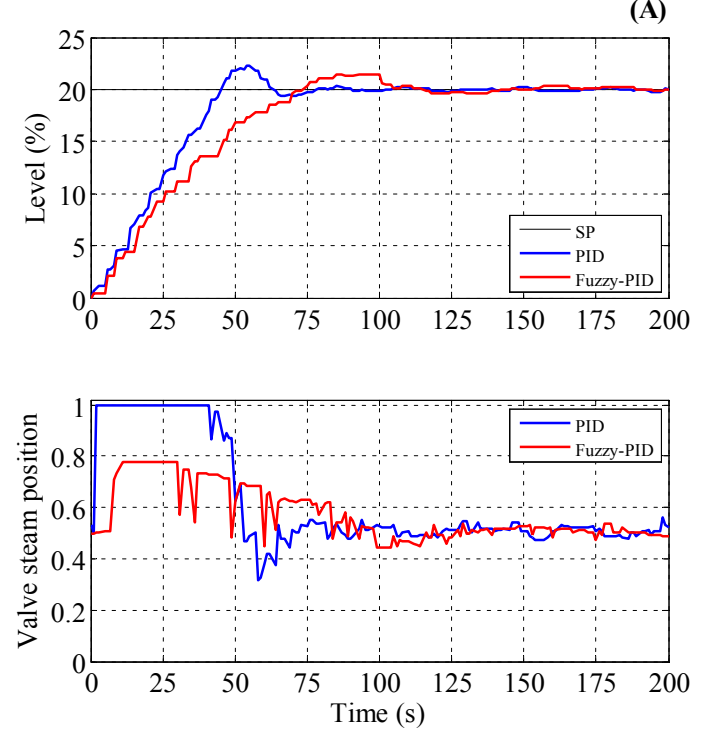

(B)
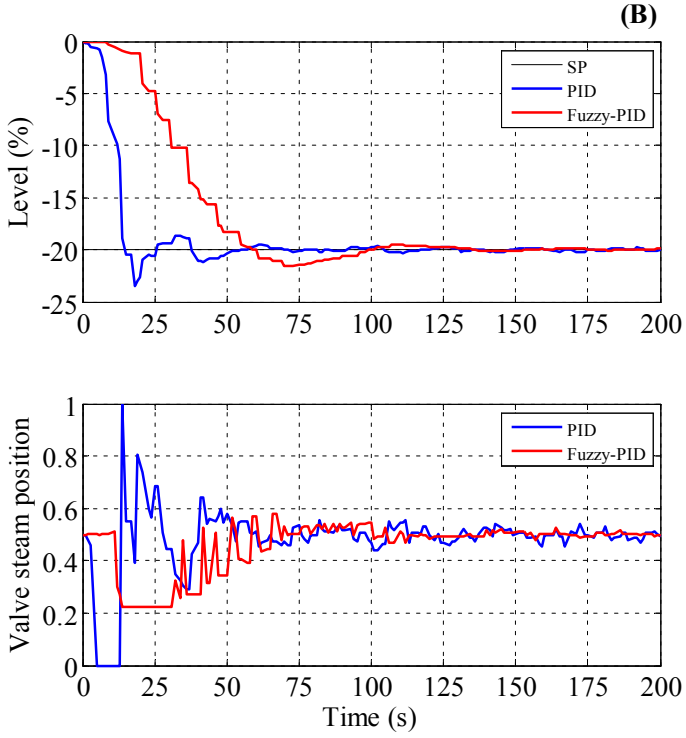

Figure 5 - Comparative behavior of fuzzy-PID and PID Controllers: (A) $+20 \%$ set point disturbances and (B) $-20 \%$ set point disturbances.

In a control system response, it is usually desired to achieve a faster rise time and suppress overshoot effectively. However, this is a difficult task because it depends on the system dynamic. In all of the aforementioned experiments, both the fuzzy-PID controller and PID controller showed a good performance. Comparing transient response parameters showed in Table 2 it was observed that fuzzy-PID led to a smaller overshoot and slower rise time than conventional PID controller. However, fuzzy-PID controller could be considered better when comparing ISE criterion, improving the response approximately $7 \%$. It is also observed in Figures 4 and 5 that there is saturation of the manipulated variable for the conventional PID controller which does not occur in the fuzzy-PID controller. This is critical to ensuring the integrity of the control valve.

Table 2 - Performance parameters of the PID and Fuzzy-PID controllers.

\begin{tabular}{lllll}
\hline Parameters & Disturbances & & & \\
\hline \multirow{2}{*}{ PID Controller } & $\mathbf{1 0} \%$ & & $\mathbf{2 0} \%$ & Pegative \\
\cline { 2 - 5 } & Positive & Negative & Positive & Neg \\
\hline ISE & 18972.7 & 19666.4 & 68828.8 & 75498.6 \\
Overshoot (\%) & 23.0 & 59.0 & 23.0 & 35.0 \\
Rise time (s) & 21.0 & 10.0 & 45.0 & 15.0 \\
\hline \multirow{2}{*}{ Fuzzy-PID Controller } & $\mathbf{1 0} \%$ & & $\mathbf{2 0} \%$ & \\
\cline { 2 - 5 } & Positive & Negative & Positive & Negative \\
\hline ISE & 18388.7 & 18785.2 & 64787.6 & 65094.0 \\
Rvershoot (\%) & 9.0 & 14.0 & 16.0 & 16.0 \\
\hline
\end{tabular}

Finally, it is important to observe that fuzzy-PID always showed a smoother control action in the valve, mainly at the beginning of response. Thus, it is possible to increase lifetime of final control devices and reduce maintenance costs. 


\section{CONCLUSIONS}

In this work, a fuzzy-PID controller was designed and implemented in a level control plant. The proposed controller was tuned by adjusting scaling gains and membership functions. A required level tank value was maintained by manipulating the stem position of the control valve. Performance of this fuzzy-PID controller was compared with a well tuned conventional PID controller through experiments under set point disturbances. The methodology of tune scaling gain based on well-tuned parameters from conventional controller could be considered a good choice to design fuzzy controller. Although it was necessary small trial-and-error adjustments in these gains, this procedure is extremely recommended to reduce the rise time of fuzzy-PID response. In spite of the fact that fuzzyPID controller showed a similar performance to conventional PID, the intelligent controller appeared to be more robust in terms of both overshoot amplitude and smooth control action criteria.

\section{REFERÊNCIAS}

APREA, C., MASTRULLO R., RENNO C. Fuzzy control of the compressor speed in a refrigerant plant. International Journal of Refrigeration 2004, 27, 639-48.

BABUSKA, R., VERBRUGGEN, H. B. An overview of fuzzy modeling for control. Control Engineering Practice 1996, 4, 1593-1606.

EKER, I., TORUN, Y. Fuzzy logic control to be conventional method. Energy Conversion and Management 2006, 47, 377-394.

EKREN, O., KUÇUKA, S. Energy saving potential of chiller system with fuzzy logic control. International Journal of Energy Research 2010, 34, 897-906.

FILETI, A. M. F., ANTUNES, A. J. B., SILVA, F. V., SILVEIRA JR, V., PEREIRA, J. A. F. R. Experimental investigations on fuzzy logic for process control. Control Engineering Practice 2007, 15:1149-1160.

FONSECA, R. R., FILETI, A. M. F., FRANCO, I. C., SILVA, F. V. Experimental Fuzzy/Split-Range Control: Novel Strategy for Biodiesel Batch Reactor Temperature Control. Chemical Engineering Communications 2016, 203, 1251-1259.

FONSECA, R. R., SCHMITZ, J. E., FILETI, A. M. F., SILVA, F. V. A fuzzy-split range control system applied to a fermentation process. Bioresource Technology 2013, 142, 475-482.

FRANCO, I. C., SCHMitz, J. E., COSTA, T. V., FILETI, A. M. F., Silva, F. V. Development of a Predictive Control Based on Takagi-Sugeno Model Applied in a Non-Linear System of Industrial Refrigeration. Chemical Engineering Communications 2017, 2014, 39-54.

FUENTE, M. J., ROBLES, C., CASADO, O., SYAFIIE, S., TADEO, F. Fuzzy control of a neutralization process. Engineering Applications of Artificial Intelligence 2006, 19, 905-914.

HABER, R. H. E; GUERRA, R. E. H. Hierarchical fuzzy controller with a self-tuning strategy an application to end milling process. Anais in: $4^{\circ} \mathrm{SBAI}-$ Simpósio Brasileiro de Automação Inteligente 1999, São Paulo, 657-662.

LEE, K. C., LEE, S., LEE, H. H. Implementation and PID tuning of network-based control systems vis Profibus polling network. Computers Standards and Interfaces 2004, 26, 
229-240.

LI, H.-X. A comparative design and tuning for a conventional fuzzy control. IEEE Transactions on Systems, Man, And Cybernetics 1997, 27, 884-889.

LI, H.-X., Gatland, H. B. Conventional fuzzy control and its enhancement. IEEE Transactions on Systems, Man, and Cybernetics 1996, 26, 791-797.

LIAO, R. F., CHAN, C. W., HROMEK, J., HUANG, G. H., HE, L. Fuzzy logic control for a petroleum separation process. Engineering Applications of Artificial Intelligence 2008, 21, 835-845.

PELUSO, M, The start up of the five Fieldbus control systems based on the IEC physical layer and on the Fieldbus Foundation specification. ISA Transactions 1996, 35, 153 158.

PRECUP, R., HELLENDOORN, H. A survey on industrial applications of fuzzy control. Computers in Industry 2011, 62, 213-226.

SANTOS, M., DEXTER, A. L. Control of a cryogenic process using a fuzzy PID scheduler. Control Engineering Practice 2002, 10, 1147-1152.

SILVA F. V., SCHMITZ J. E., NEVES FILHO L. C., FILETI A. M. F., SILVEIRA JUNIOR V. Saving energy using fuzzy control applied to a chiller: an experimental study. Clean Technology Environment Policy 2011, 14, 535-542.

VIDAL, S. F. S., SCHMITZ, J. E., FRANCO, I. C., FILETI, A. M. F., SILVA, F. V. Fuzzy Multivariable Control Strategy Applied to a Refrigeration System. Chemical Product and Process Modeling 2016, DOI: 10.1515/cppm-2016-0033.

WAKABAYASHI, C., EMBIRUCU, M., FONTES, C., KALID, R. Fuzzy control of a nylon polymerization semi-batch reactor. Fuzzy Sets and Systems 2009, 160, 537-553.

ZADEH, L. Fuzzy sets. Information and Control 1965, 8, 338-353. 